\title{
Facing the challenges of distribution systems operation with high wind power penetration
}

Das, Kaushik; Altin, Müfit; Hansen, Anca Daniela; Nuño Martinez, Edgar; Sørensen, Poul E.; Thybo, Gitte Wad; Rangård , Michael; Skytte, Kasper Møller

\section{Published in:}

Proceedings of the 12th IEEE Power and Energy Society PowerTech Conference

Link to article, DOI:

10.1109/PTC.2017.7981136

Publication date:

2017

Document Version

Peer reviewed version

Link back to DTU Orbit

Citation (APA):

Das, K., Altin, M., Hansen, A. D., Nuño Martinez, E., Sørensen, P. E., Thybo, G. W., Rangård , M., \& Skytte, K. M. (2017). Facing the challenges of distribution systems operation with high wind power penetration. In Proceedings óf the 12th IEEE Power and Energy Society PowerTech Conference IEEE. https://doi.org/10.1109/PTC.2017.7981136

\section{General rights}

Copyright and moral rights for the publications made accessible in the public portal are retained by the authors and/or other copyright owners and it is a condition of accessing publications that users recognise and abide by the legal requirements associated with these rights.

- Users may download and print one copy of any publication from the public portal for the purpose of private study or research.

- You may not further distribute the material or use it for any profit-making activity or commercial gain

- You may freely distribute the URL identifying the publication in the public portal 


\section{Facing the challenges of distribution systems operation with high wind power penetration}

\author{
Kaushik Das*, Edgar Nuño Martinez, Müfit Altin, \\ Anca D Hansen, Poul E Sørensen \\ Department of Wind Energy \\ Technical University of Denmark \\ Ris $\varnothing$ Campus, Roskilde, Denmark \\ *kdas@dtu.dk
}

\author{
Gitte Wad Thybo, Michael Rangård, \\ Kasper Møller Skytte \\ Eniig \\ Silkeborg, Denmark
}

\begin{abstract}
This paper addresses the challenges associated with the operation of a distribution system with high penetration of wind power. The paper presents some preliminary investigations of an ongoing Danish research work, which has as main objective to reduce the network losses by optimizing the reactive power flow in $60 \mathrm{kV}$ distribution networks through controlling the ability of wind power plants (WPPs) to generate or absorb reactive power. This paper aims to understand the characteristics of a distribution network with high penetration of distributed generation. A detailed analysis of the active and reactive power flows in a real distribution network under different wind and load conditions based on actual measurements is performed in order to understand the correlation between the consumption, wind power production, and the network losses. Conclusive remarks are presented, briefly expressing the track for the future work.
\end{abstract}

Index Terms-Distributed wind generation, distribution system, network loss, wind turbine capabilities

\section{INTRODUCTION}

According to Danish TSO, Energinet.dk, the total distributed generation (DG) installed capacity in Denmark in 2013 was around 6.6 GW where the wind turbines (WTs) had the highest share as $53 \%(3.5 \mathrm{GW})$ [1]. The integration of these WTs in the distribution networks offers several benefits, like reducing congestions and power losses in the transmission lines, active support in terms of voltage stability, improved load shedding [2] etc. Due to improvement in technologies and reducing costs, wind turbines are becoming prevalent choice among different DG options to support the network. This also has added benefit of low environmental impact. However, high penetration of DGs, like wind power and photovoltaic power PV, without contorl may also challenge operations of the distribution networks economically. For example, the electricity production from the WTs has an impact on the network losses that may change the reactive power flow and thus the variation of the voltage profile throughout the distribution feeders. Whenever there is excess power production from WTs compared to the consumption in the connected substation transformer, the network losses will be changed in

The work is carried out by the DTU Wind Energy Department in cooperation and collaboration with Eniig and Dansk Energi. The Danish PSOprogramme ForskEL, which is administered by Energinet.DK, is acknowledged for funding this work in contract number POS project no. 12433 (NetVind). transformers and cables depending on the network topology. Furthermore, large concentration of WTs in the distribution network can also generate local power imbalances that have to be planked out/compensated in the $150 / 60 \mathrm{kV}$ transformer substations.

Relatively large reactive power can flow between $150 \mathrm{kV}$ and $60 \mathrm{kV}$ networks especially in high wind speed conditions [3]. This transfer of reactive power reduces the capacity of the lines causing network losses. To prevent large reactive power exchange between the distribution and transmission grids, the network operators impose explicit limits on reactive power flow through transformers. For instance, Energinet.dk has defined a regulation for the operational band for the reactive power exchange between the $60 \mathrm{kV}$ distribution and $150 \mathrm{kV}$ transmission networks [4]. The idea of such regulation is to ensure a reactive power balance and thus a stable voltage in the distribution network, limiting the losses caused by transport of active power. Additionally, these losses in $60 \mathrm{kV}$ are not compensated by economic regulations.

Several studies has been done regarding impact of high penetration of distributed generation towards distribution system losses. Many studies have been done with respect to loss allocation with DG [5], [6]. Quezada et. al. [7] assess the qualitative nature of losses to understand the influence of DG penetration that affect annual losses variations. Costa and Matos [8] study the variation of losses due to the influences of distributed generation. Lund [9] presents an investigation of the active and reactive power losses in a distribution network with wind turbines and combined heat and power plants. Soder [10] and Mutale et. al. [11] proposed method to compute marginal losses per node. Shaloudegi et. al. [12] proposed a strategy for locational marginal price allocation based on loss allocation. All of these studies assume that the location and capacity of the DG in the MV network are known. However, there can be substantial amount of DG can be embedded in the LV network without the exact knowledge of location and capacity. Loss allocation can be challenging and inaccurate in such situations. Many studies have been performed regarding loss minimization in the distribution networks through optimal DG placement [13]-[16]. References [17]-[19] use network reconfiguration for minimizing loss in distribution system 
with high penetration of DG. Kalambe and Agnihotri [20] provide a survey for different loss minimization techniques in distribution network.

The goal of this paper is to address the challenges associated with the operation of a distribution system with high penetration of wind power by analyzing the impact of wind power generation on the distribution network losses based on real measurements. The characteristics of a specific distribution network are studied with respect to power flow, losses, generation and loads. The first step toward understanding how to reduce the network losses is to analyze the active and reactive power flow in the network by identifying where the power is produced in the network; where it is consumed and which controlled power resources are available. The aim of this paper is therefore to analyze the active and reactive power flow in a real distribution network under different wind and load conditions. Load flow calculations are performed based on a distribution grid model using the real-time measurements. All the studies are done without any reactive power support from controllable WPPs. Grid losses due to active and reactive power production from wind turbines are then calculated based on these load flow calculations. The study is carried out through simulations with a Danish distribution network model. The model, which is implemented in DigSilent PowerFactory, is validated and if necessary updated based on actual measurements in the distribution network. A method to estimate the network operational mode is developed based on "snap-shot" measurements.

\section{Danish Research Project NetVind}

The overall objective of NetVind is to improve the operation of a real distribution network with a high penetration of wind power by exploiting WPP control capabilities. With an increased penetration of wind energy into the power distribution systems, the local network companies face many challenges in how to operate the distribution system by using WPPs as controllable components into the system. This means that WPPs should share some of the duties carried out today by the conventional power plants, such as regulating reactive power and performing voltage control on the grid.

The attention in the present research project is directed toward on how to reduce network losses due to transport of the active power additionally produced by wind turbines by optimizing the reactive power flow, and to reduce the loss of power production from WPPs during disconnections due to the repair and maintenance of the network. The research is done in two stages.

In the first stage, an offline analysis is performed as illustrated in Fig. 1 having as output a set of recommendations regarding algorithms to either: (I) to optimize the reactive power flow and thus minimize the power losses or (II) to reduce the loss of power production from WTs during disconnections due to the repair and maintenance of the network. A detailed analysis of the active and reactive power flow in a specific/realistic distribution grid under different wind and load conditions are performed based on simulations of a distribution grid model and real measurements. Once the grid losses due to active and reactive power production from WPPs are calculated based on a series of load flow calculations through simulations with a Danish distribution network model, different optimization algorithms are analyzed through employing the ability of WTs to generate as well as absorb reactive power. Special attention in this project is on how the WPPs reactive power control capability can be used to control the flow of reactive power in the network, while voltage and grid load are kept within limits.

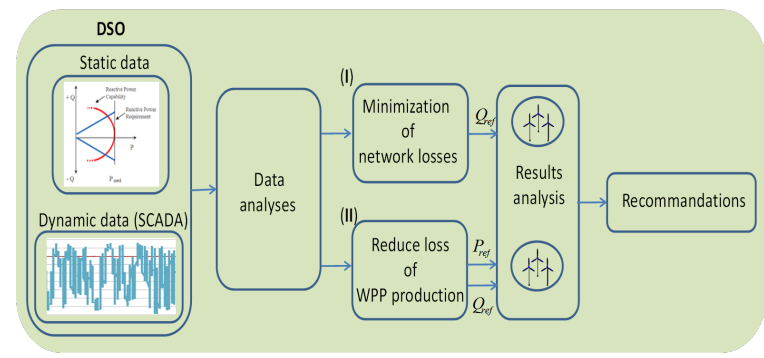

Fig. 1. Offline Analysis

The distribution system operator typically choose to shut down the WPPs in order to make sure that the network does not get overloaded during maintenance of network components like cables, transformers etc. However, in many of such situations it is sufficient to limit wind power production rather than shutting it down. The idea is to use the WPPs set-points to limit the wind power production while avoiding network congestions. As illustrated in Fig. 1, the first stage also investigates the potential for reduction of loss of wind power production rather than shutting it down during maintenance of the distribution network. Probable specific disconnections in the network will be analyzed for different wind and load conditions in the situation where the WPPs are ordered to shut down. The feasibility of using power set-points for the WPPs to ensure a reduction in wind power production and thereby prevent network overloading will be analyzed. Finally, the reduction of wind power production loss will be calculated.

In stage 2, the different algorithms developed in the offline analysis are implemented and validated online in a real distribution power system, as depicted in Fig. 2. The model, which is implemented in PowerFactory, will be validated and if necessary updated based on actual measurements in the distribution network.

\section{DATA ANALYSIS}

\section{A. Network Model}

Fig. 3 shows the $150 / 60 \mathrm{kV}$ distribution substation considered for the present investigations. It consists of following:

- 26 numbers of $60 / 10 \mathrm{kV}$ substations which can be classified into 3 categories:

- Substations which act as demands solely and consume active power. 


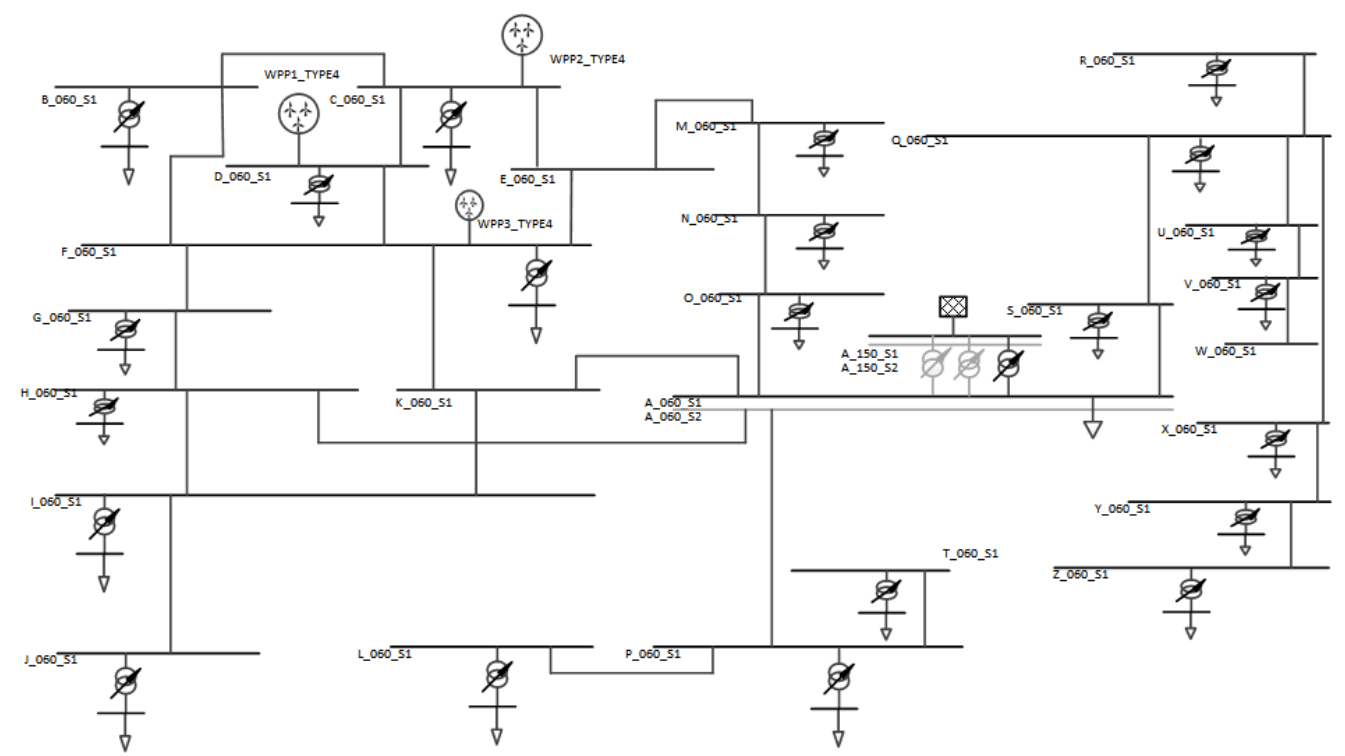

Fig. 3. $150 \mathrm{kV}$ Distribution Substation Model

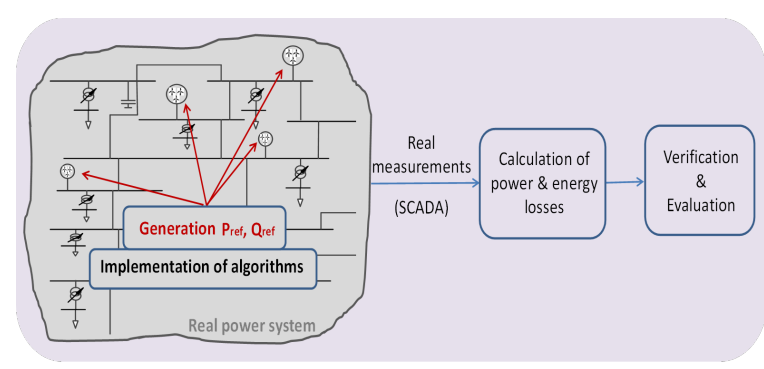

Fig. 2. Online Operation

- Substations which behave as prosumers with uncontrollable generators connected at voltage levels less than equal to $10 \mathrm{kV}$.

- Substations which behave as prosumers with controllable WPPs connected at $60 \mathrm{kV}$. both as generator and demand. Henceforth, wind power generation from only these WPPs are referred in this paper.

- 3 controllable WPPs

- Loads and other generations (CHPs, PV etc.) are connected at $10 \mathrm{kV}$ or lower voltage levels. These sources are aggregated together.

As depicted in Fig. 1, two types of data are available in the analysis:

- Static data which comprise of network topology data, transformer data, WPP data, P-Q capability curve of WTs etc.

- Dynamic data which consist of SCADA measurements of active power, reactive power, voltage and current from $150 \mathrm{kV}$ and $60 \mathrm{kV}$ bus bars and feeders.

In this paper, dynamic data from December 2014 to September 2015 at a resolution of 1 hour are collected and analyzed. The characteristics of these data are presented in Table I.

TABLE I

SYSTEM CHARACTERISTICS

\begin{tabular}{c|c}
\hline Max. Loading (Consumption) at 150 kV Substation (MW) & 58.38 \\
\hline Avg. Loading at 150 kV Substation (MW) & -8.19 \\
\hline Max. Loading (Generation) at $150 \mathrm{kV}$ Substation (MW) & 103.04 \\
\hline Max. Wind Power Generation from Controllable WPPs (MW) & 40.6 \\
\hline Avg. Wind Power Generation from Controllable WPPs (MW) & 13.2 \\
\hline
\end{tabular}

In order to analyze the losses in the $60 \mathrm{kV}$ feeders a simple methodology is used as described below.

\section{B. Loss Calculation Methodolgy}

The offline algorithm for loss calculation is as following:

1) Set time counter to zero

2) Receive active power, reactive power, voltage, current measurements for current hour

3) Run filtering and state estimation for filling missing data and eliminating measurement noise, bad data

4) Set active power, reactive power for PQ buses and active power, voltage for PV buses

5) Run power flow analysis

6) Calculate losses in $60 \mathrm{kV}$ feeders

7) Increase time counter by 1 hour

8) Continue for the whole time series

9) Calculate energy losses and perform statistical data analysis

Statistical analyses of time series for load, wind power generation and power loss are performed to understand the behavior and correlation between these variables. 


\section{Timeseries Analysis}

In order to understand the characteristics of the distribution network, P-Q plot for the total load connected at $10 \mathrm{kV}$ are plotted in Fig. 4. Notice that when total active power load is negative i.e. demand is less than the generation connected at $10 \mathrm{kV}$; reactive power consumption is positive. This can be attributed to high penetration of uncontrollable fixed speed wind turbines connected below $10 \mathrm{kV}$. These kind of WTs consist of induction generators, which consume reactive power while generating active power.

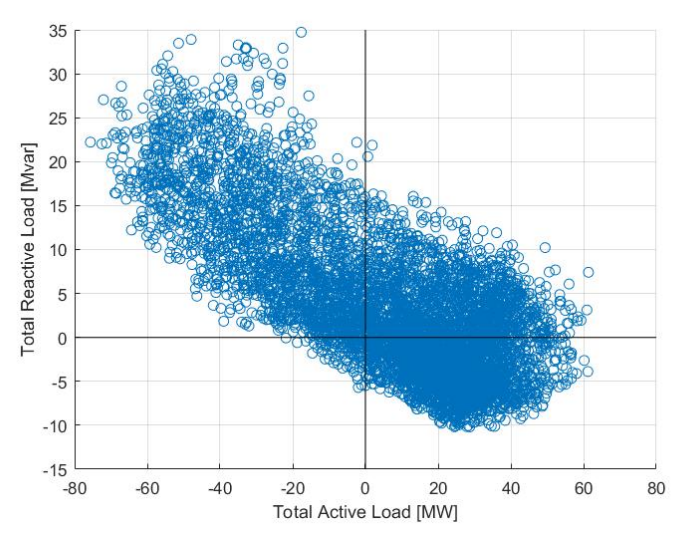

Fig. 4. P-Q plot for the total load connected at $10 \mathrm{kV}$

In order to understand the impact of wind power generation on network losses; a representative time series of active power loss and wind power generation for 450 hours are plotted in Fig. 5. Since the peaks of wind power generations are coordinated with the peaks of active power loss, Fig. 5 graphically suggests that high wind power generation might be driving the losses in this system.

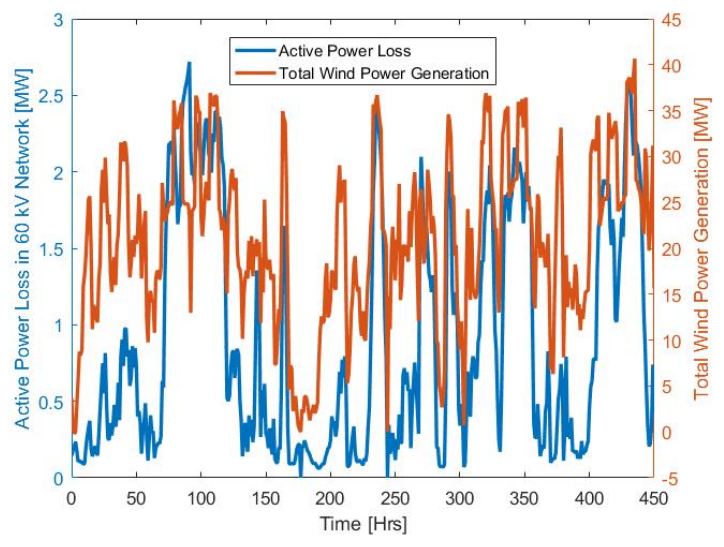

Fig. 5. Representative time series of active power loss and total wind power generation with 1 hour resolution

The probabilities of having losses greater or equal than $2 \mathrm{MW}$ for the actual wind power production (represented by capacity factor) is derived. Equation 1 calculates the probability of loss $\geq 2 \mathrm{MW}$, when each of the individual WPP are operating at a specific capacity factor, $C F_{i}$ (Equation 2). While, Equation 3 calculates the probability of loss $\geq 2 \mathrm{MW}$, when all the WPPs are operating at specific capacity factor, $C F_{\text {all }}$ (Equation 4).

$$
\operatorname{Pr}_{i}(x)=\operatorname{Prob}\left(\text { loss } \geq 2 M W \mid C F_{i}=x \forall i=1,2,3\right)
$$

where,

$$
\begin{gathered}
C F_{i}=\frac{\operatorname{Gen}_{W P P_{i}}}{\operatorname{Capacity}_{W P P_{i}}} \forall i=1,2,3 \\
\operatorname{Pr}_{\text {all }}(x)=\operatorname{Prob}\left(\text { loss }>2 M W \mid C F_{\text {all }}=x\right)
\end{gathered}
$$

where,

$$
C F_{\text {all }}=\frac{\sum_{i=1}^{3} \operatorname{Gen}_{W P P_{i}}}{\sum_{i=1}^{3} \text { Capacity }_{W P P_{i}}}
$$

These probabilities are plotted against specific capacity factor $(C F=x)$ in Fig. 6. $P r_{i}$ and $P r_{\text {all }}$ follow more

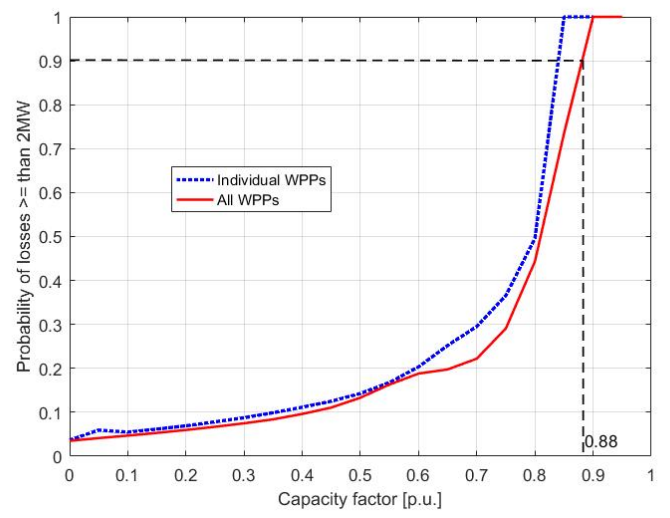

Fig. 6. Probability of loss $\geq 2 \mathrm{MW}$ for different capacity factors

or less each other for CF lower than 0.6, while at higher $\mathrm{CF}$, the probability of losses for individual WPPs is higher that the losses for $\mathrm{CF}$ for total wind power. Notice that, for capacity factor 0.8 and above, losses start increasing fast. For example, the probability of having these losses is $90 \%$ when the production is at least $88 \%$ of the rated capacity from all the WPPs.

It is also important to find the number of hours when WPPs are operating at high capacity factor. Duration curve for wind power generation is shown in Fig. 7. It can be observed that high wind power generation (capacity factor $\geq 0.5$ i.e. 21 MW) only occurs for 1673 hours, i.e. only $24.9 \%$ of the total considered period. While capacity factor $\geq 0.7=29.4 M \mathrm{~W}$ occurs only for 559 hours (8.3\%). Duration curve for power loss in $60 \mathrm{kV}$ network is shown in Fig. 8. It can be seen that, loss higher than $2 \mathrm{MW}$ merely happens for 222 hours, i.e., $3 \%$ of the total considered period. Fig. 6, Fig. 7 \& Fig. 8 show that high losses and high wind power generation occur for a relatively small portion of the total time.

Fig. 9 shows the number of hours WPPs are operated at different bins of capacity factors $\left(C F_{\text {all }}\right)$. It can be seen that 


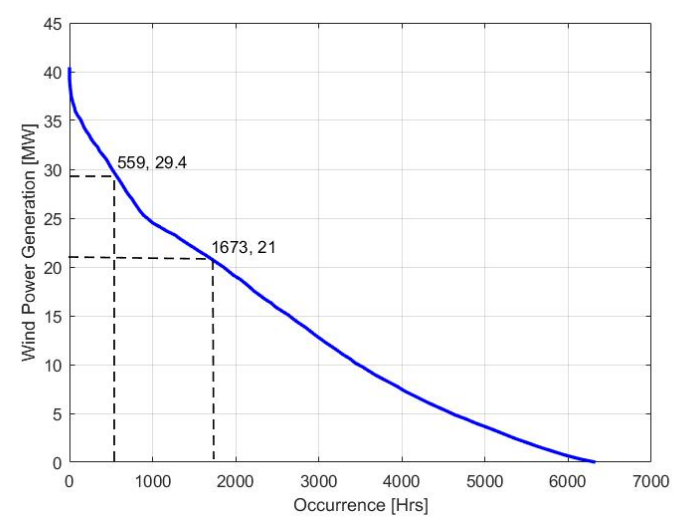

Fig. 7. Duration curve for Wind Power Generation

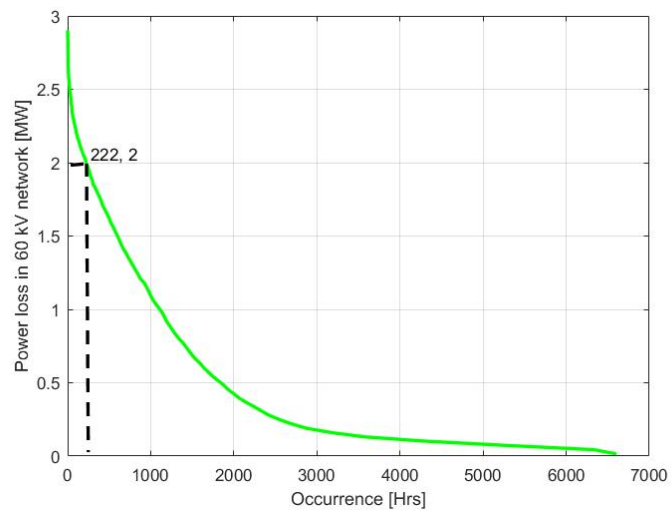

Fig. 8. Duration curve for power loss in $60 \mathrm{kV}$ network

the WPPs operate for lower number of hours at high capacity factor as compared to low capacity factors. Fig. 10 shows the energy loss occurring in the $60 \mathrm{kV}$ network for different bins of capacity factors of all WPPs $\left(C F_{\text {all }}\right)$. For instance, energy loss is $341 \mathrm{MWh}$ when WPP capacity factor is between [0.4 0.5]. It can be observed from the shaded region of Fig. 10 that major proportion of energy loss occurs when wind power generation is high (capacity factor $\geq 0.5$ ), although number of hours are less for these capacity factors (Fig. 9). Table II provides the total energy loss in the system as well as energy loss during high and low wind power scenarios. Notice that $71 \%$ of the energy loss happen when wind power generation is more than $50 \%$ of its capacity.

TABLE II

ENERGY LOSS

\begin{tabular}{c|c}
\hline Energy loss in the considered period (MWh) & 3081 \\
\hline $\begin{array}{c}\text { Energy loss during high wind power generation }(\mathrm{MWh}) \\
\text { (capacity factor }>50 \%)\end{array}$ & 2179 \\
\hline Energy loss during low wind power generation (MWh) & 902 \\
\hline
\end{tabular}

Another important point to be considered is the reactive power consumption by $60 \mathrm{kV}$ distribution network during

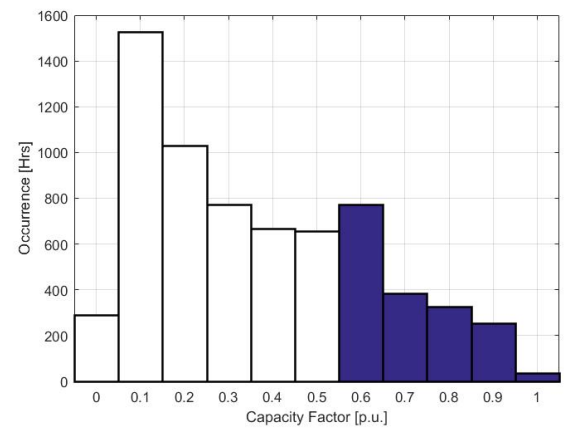

Fig. 9. Operational hours for WPPs at different capacity factors

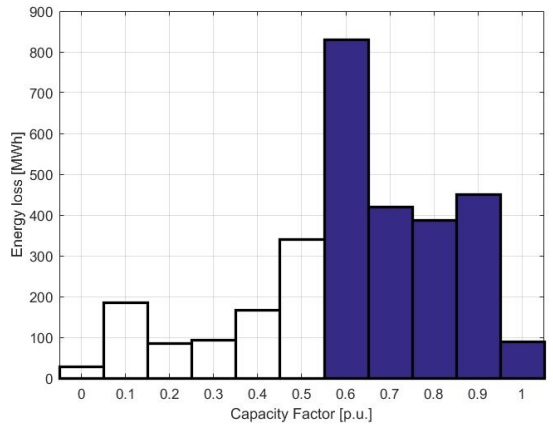

Fig. 10. Energy loss in the $60 \mathrm{kV}$ network for different WPP capacity factors

different wind power scenarios. Scatter plot between reactive power consumption by $60 \mathrm{kV}$ network and wind power generation is shown in Fig. 11. It is obviously clear from Fig. 11 that higher the wind power generation, the higher is reactive power consumption by the network. The reason for this is that the cables are highly loaded during high wind power scenarios resulting in increased consumption of reactive power. When wind power generation is low as well as system is lightly loaded, cables act as capacitors resulting in generation of reactive power by the distribution network.

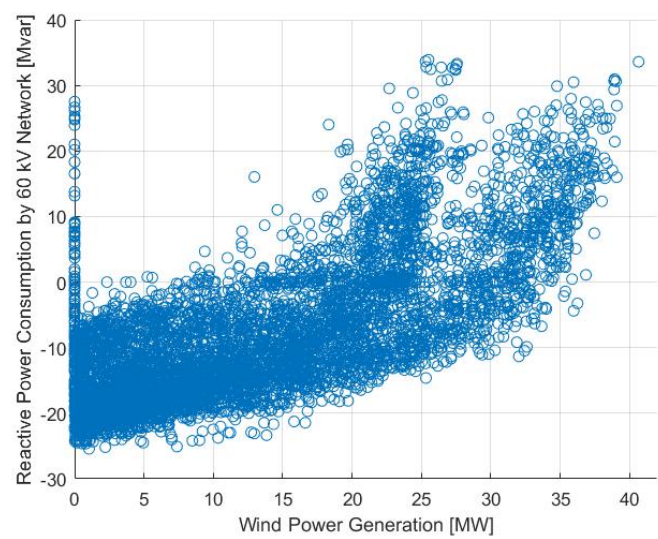

Fig. 11. Scatter plot between reactive power consumption by $60 \mathrm{kV}$ network and wind power generation 
High reactive power flow from transmission network can have many adverse effects like increased losses, low voltage, network congestion and may even result in voltage instability. It is advisable that the distribution system satisfies locally the reactive power requirements to avoid these situations.

It should be mentioned that all the above studies are done without any reactive power support from controllable WPPs. In the next step of the investigation, the control capabilities of WPPs will be used to minimize the losses. A set of requirements for WPPs are presented in the grid codes [21] require that the WPPs have certain reactive power generation capabilities in order to be connected to the system. Dansh grid code requirements for reactive power control functions for a WPP is shown in Fig. 12. Reactive power generation capabilities from WTs are dependent on voltage and active power generation. However, WPPs may have additional controllable devices such as capacitor bank or shunt reactors to provide required reactive power capabilities.

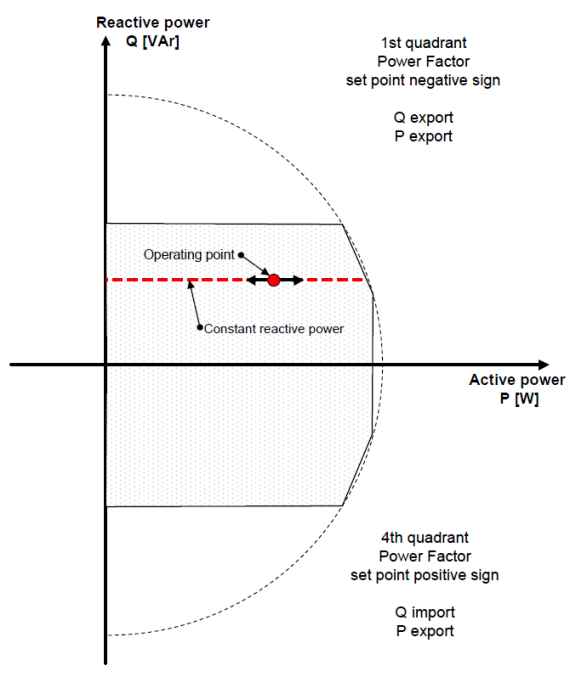

Fig. 12. Reactive power control functions for a wind power plant [21]

Currently there is no requirement for generating reactive power from the WPPs connected in Danish distribution systems. However, reactive power control from WPPs can be helpful in reducing network loss and improving voltage profile in active distribution network, this being in focus in the next step of present research.

\section{CONCLUSiON}

Time series of real measurements from a distribution system with high penetration of DGs are analyzed in this paper. The analysis has shown that the higher is wind power generation, the higher is network loss. Although high wind power generation occurs for small duration, it contributes for major proportion of energy loss. The results of this work can be used as a starting base in the next step of the investigation necessary to develop a methodology to minimize the losses in the distribution network by exploiting WPP capabilities to absorb or consume reactive power.

\section{REFERENCES}

[1] K. L. Anaya and M. G. Pollitt, "Integrating distributed generation: Regulation and trends in three leading countries," Energy Policy, vol. 85, pp. $475-486,2015$.

[2] K. Das, A. Nitsas, M. Altin, A. D. Hansen, and P. Sørensen, "Improved Load Shedding Scheme considering Distributed Generation," IEEE Transactions on Power Delivery, 2016.

[3] T. Lund, J. E. Nielsen, P. Hylle, P. E. Sørensen, A. H. Nielsen, and G. Sørensen, "Reactive power balance in a distribution network with wind farms and chps," International Journal of Distributed Energy Resources, 2007.

[4] Energinet.Dk, "Teknisk forskrift: TF 2.1.3 dansk mvar-ordning," 2010. [Online]. Available: https://www.energinet.dk/SiteCollectionDocuments/ Danske\%20dokumenter/El/Mvar\%20Ordning.pdf

[5] Z. Ghofrani-Jahromi, Z. Mahmoodzadeh, and M. Ehsan, "Distribution loss allocation for radial systems including dgs," IEEE Transactions on Power Delivery, vol. 29, no. 1, pp. 72-80, 2014.

[6] M. Atanasovski and R. Taleski, "Energy summation method for loss allocation in radial distribution networks with dg," IEEE Transactions on Power Systems, vol. 27, no. 3, pp. 1433-1440, 2012.

[7] V. M. Quezada, J. R. Abbad, and T. G. S. Roman, "Assessment of energy distribution losses for increasing penetration of distributed generation," IEEE Transactions on Power Systems, vol. 21, no. 2, pp. 533-540, 2006.

[8] P. M. Costa and M. A. Matos, "Loss allocation in distribution networks with embedded generation," IEEE Transactions on Power Systems, vol. 19 , no. 1, pp. 384-389, 2004.

[9] T. Lund, "Measurement based analysis of active and reactive power losses in a distribution network with wind farms and chps," in 2007 European Wind Energy Conference and Exhibition, 2007.

[10] L. Söder, "Estimation of reduced electrical distribution losses depending on dispersed small scale energy production," in Proc 12th PSCC, vol. 2, 1996, pp. $1229-1234$.

[11] J. Mutale, G. Strbac, S. Curcic, and N. Jenkins, "Allocation of losses in distribution systems with embedded generation," IEE ProceedingsGeneration, Transmission and Distribution, vol. 147, no. 1, pp. 7-14, 2000.

[12] K. Shaloudegi, N. Madinehi, S. Hosseinian, and H. A. Abyaneh, "A novel policy for locational marginal price calculation in distribution systems based on loss reduction allocation using game theory," IEEE Transactions on Power Systems, vol. 27, no. 2, pp. 811-820, 2012.

[13] K. Mahmoud, N. Yorino, and A. Ahmed, "Optimal distributed generation allocation in distribution systems for loss minimization," IEEE Transactions on Power Systems, vol. 31, no. 2, pp. 960-969, 2016.

[14] M. Vatani, D. S. Alkaran, M. J. Sanjari, and G. B. Gharehpetian, "Multiple distributed generation units allocation in distribution network for loss reduction based on a combination of analytical and genetic algorithm methods," IET Generation, Transmission \& Distribution, vol. 10, no. 1 , pp. 66-72, 2016.

[15] D. Q. Hung and N. Mithulananthan, "Multiple distributed generator placement in primary distribution networks for loss reduction," IEEE Transactions on industrial electronics, vol. 60, no. 4, pp. 1700-1708, 2013.

[16] L. F. Ochoa and G. P. Harrison, "Minimizing energy losses: Optimal accommodation and smart operation of renewable distributed generation," IEEE Transactions on Power Systems, vol. 26, no. 1, pp. 198-205, 2011.

[17] H. R. Esmaeilian and R. Fadaeinedjad, "Energy loss minimization in distribution systems utilizing an enhanced reconfiguration method integrating distributed generation," IEEE Systems Journal, vol. 9, no. 4, pp. $1430-1439,2015$

[18] A. M. Tahboub, V. R. Pandi, and H. Zeineldin, "Distribution system reconfiguration for annual energy loss reduction considering variable distributed generation profiles," IEEE Transactions on Power Delivery, vol. 30, no. 4, pp. 1677-1685, 2015.

[19] R. S. Rao, K. Ravindra, K. Satish, and S. Narasimham, "Power loss minimization in distribution system using network reconfiguration in the presence of distributed generation," IEEE transactions on power systems, vol. 28, no. 1, pp. 317-325, 2013.

[20] S. Kalambe and G. Agnihotri, "Loss minimization techniques used in distribution network: bibliographical survey," renewable and sustainable energy reviews, vol. 29, pp. 184-200, 2014.

[21] Energinet.DK, "Technical regulation 3.2.5 for wind power plants above 11 kW," Technical report, Tech. Rep., 2016. 